\title{
Production and planned in-orbit qualification of a function-integrated, additive manufactured satellite sandwich structure with embedded automotive electronics
}

\author{
M. Echsel ${ }^{1}$ (D) P. Springer ${ }^{1} \cdot$ S. Hümbert ${ }^{2}$
}

Received: 31 January 2020 / Revised: 10 June 2020 / Accepted: 13 July 2020 / Published online: 25 July 2020

(c) The Author(s) 2020

\begin{abstract}
As part of the Integrated Research Platform for Affordable Satellites project, the German Aerospace Center, the Fraunhofer Institute for Manufacturing Engineering and Automation and the Institute for Space Systems at the University of Stuttgart are investigating new ways of manufacturing satellites more cost-effectively in the future. One of the investigated approaches is a new way of producing structural stalleite elements to save weight, volume and, therefore, costs. This publication presents a functional integrated satellite structure that combines the potentials of additive manufacturing of thermoplastics and miniaturized automotive electronics. The structures' base is a sandwich with a printed core in which both, the wire harness and automotive micro-electromechanical systems sensors for position and thermal control are integrated. The partial aspects of additive manufacturing and the use of modern automotive electronics were investigated and assesed. In addition, an in-orbit experiment will be presented to evaluate the structure under real conditions.
\end{abstract}

Keywords Small satellite $\cdot$ Additive manufacturing $\cdot$ Automotive electronics $\cdot$ IRAS $\cdot 3 D$-printing $\cdot$ Cost reduction

\section{Introduction}

The space industry is currently undergoing global upheaval, driven by the NewSpace sector and satellite-based constellation companies [1]. Worldwide companies, such as OneWeb, SpaceX [2], Samsung and Boeing, are working to build networks from 600 to 4000 [3] satellites in low earth orbit (LEO) or up to 7500 satellites in very low earth orbit (VLEO) [2]. These so-called constellations can be used, for example, as data transmission networks and, thus, enable the worldwide availability of fast Internet access [4, 5], can be used for Earth observation or scientific purposes [6].

The economic success of these constellations depends on the unit costs of the satellites and the expenses to get the satellite to its operating orbit, as well as the operating scenario. At the same time, small satellites are changing the

M. Echsel

markus.echsel@ipa.fraunhofer.de

$1 \quad$ Fraunhofer Institute for Manufacturing Engineering and Automation, Stuttgart, Germany

2 German Aerospace Center (DLR) Institute of Structures and Design, Stuttgart, Germany established cost structures $[7,8]$. Together with the acceptance of higher failure probabilities, significantly reduced service life and new end-of-life concepts, this leads to enormous changes in the architecture and production of satellites $[9,10]$. In order to succeed in this increasingly dynamic and cost-driven competition, the space industry must break new ground in technology, development, production and cooperation.

Within the project Integrated Research Platform for Affordable Satellites (IRAS), the consortium, consisting of the German Aerospace Center (DLR), the Fraunhofer Institute for Manufacturing Engineering and Automation (IPA) and the Institute for Space Systems of the University of Stuttgart (IRS), is investigating new ways to produce satellites more cost-effectively in the future. In the series production of satellites for future mega constellations, the knowhow from existing industries can be used advantageously to reduce costs through technology transfer. The project, therefore, investigates the use of automotive electronics and additive manufacturing processes to save volume and weight of constellation satellites and generates cost advantages [10].

In order to investigate the influences on the component costs of a satellite, the use of Commercials Off-The-Shelf (COTS) from the automotive sector, the use of additive 
manufacturing processes and the combination of both approaches to a function-integrated structure are presented in the following chapters.

\section{Automotive electronics}

Due to the progressive development in the field of autonomous driving, the demands on reliability and fail-safety of the electronic components are increasing. Accordingly, highly reliable and at the same time very cost-effective components with high potential for the satellite industry are becoming available in the market. Therefore, a way of designing satellites more cost-effective is the use of COTS components from the automotive sector. Magnetic sensors in particular are highly promising candidates for space applications [11]. The qualification standards for automotive and aerospace applications differ in some areas, especially in the field of radiation investigations. Here, new material compounds could offer possibilities for selective shielding [12] and enable the use of a greater bandwidth of COTS.

The degree of integration density of electronic components in automotive electronics is typically significantly higher than in classic space components. The use of automotive electronics, thus, promises great potential for miniaturization and at the same time in cost savings.

In order to improve the functional density of satellites and their structural elements, the integration of electronics into structural elements is now to be investigated. Therefore, typical automotive components are used, and their suitability for satellite construction is evaluated. The radiation resistance of the considered components is tested experimentally and possible shielding strategies are developed. The results should then lead to a process that will allow automotive electronics to be qualified for satellite construction with minimal effort in the future.

COTS have long provided an incentive for use in space missions [13]. The advantages, such as greater performance, lower acquisition costs, more functionality, smaller volumes or even better energy efficiency, are bought at the price of supposed disadvantages in the reliability of these components.

Since automotive electronics cannot easily be used in a space mission without an expensive qualification process, the initial requirements for components must be clarified. For this purpose, the standards that apply to integrated circuits (ICs) in the automotive sector (AEC-Q100) and the current ESA standards (ECSS-Q-ST-60-13C) have been compared and assessed according to their test criteria and permissible limits. Already in a first comparison, it is noticeable that the requirements for the components correspond in large areas of the standards or are very well comparable.
To make it easier to identify parallels, the standards are subdivided and re-categorized according to their individual test procedures. This results in a general overview of the areas in which a qualification process typically takes place. These areas are shown in Table 1 as well as a short comment which describes their comparability between the different standards.

From the preceding studies on comparability, steps can be derived which help to close the gaps between the automotive and the space standardizations. Since the automotive standard sometimes even requires the same test procedures, additional qualification is only necessary in categories that are not meant to be tested or meant to be tested to a lower extent. In particular, the missing test procedure in regard to radiation resistance is noticeable-this is a specification, which is not intended to be tested in the automotive sector.

Particularly interesting electronic components are those that are either not available as space-grade components or the ones where the space-grade components are very expensive, have a large format factors or a functional disadvantages compared to automotive electronics.

Therefore, components from different areas are selected which can have a particularly high-saving potential for satellite production. These areas include classical power electronics, common semiconductors and micro-electromechanical systems (MEMS).

Components qualified to AEC-Q100 typically undergo rigorous process controls during manufacturing. These process controls reflect the quality of the manufacturing process and, thus, have a direct influence on the reproducibility and consistent quality of the components. With regard to the reliability of the components, however, qualification tests of the individual components (typically on a random sample basis) are used.

Figure 1 shows three printed circuit boards (PCB) where the differences in size can be seen. The left PCB is equipped with a space-graded MEMS sensor and is manufactured with the design guidelines of the ECSS-Q-ST-70$12 \mathrm{C}$ in mind. To compare the performance of automotive electronics, a MEMS sensor with similar specifications

Table 1 Comparability of qualification standards

\begin{tabular}{ll}
\hline Testing categories & comparability \\
\hline Accelerated environment stress tests & Excellently comparable \\
Accelerated lifetime simulation tests & Highly comparable \\
Package assembly integrity tests & Highly comparable \\
Cavity package integrity tests & Slight differences in \\
& "mechanical shock" \\
& and "vibration" \\
Radiation evaluation & Qualification in auto- \\
& motive standards not \\
foreseen
\end{tabular}



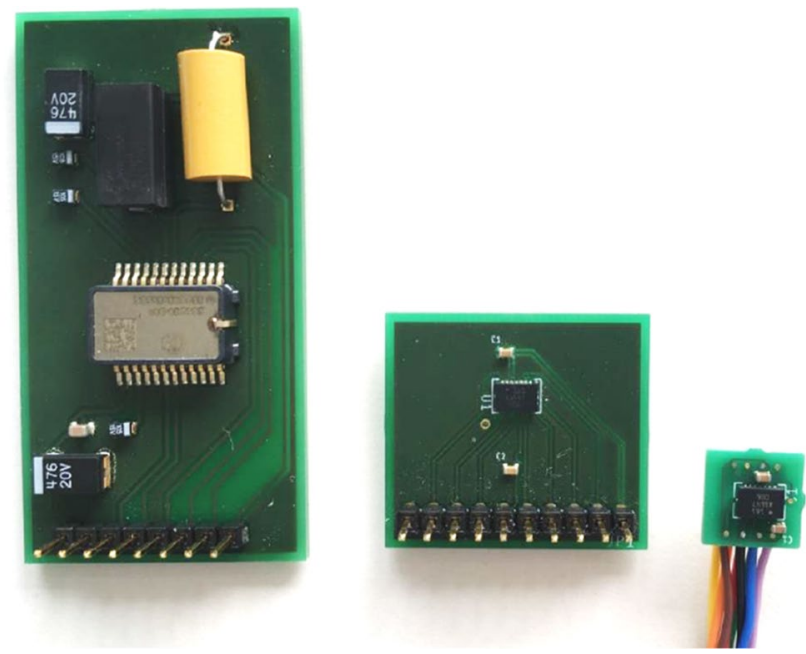

Fig. 1 Left: board with space components and space manufacturing guidelines; middle: board with automotive components (space manufacturing guidelines), right: board with automotive components and adapted manufacturing guidelines

regarding accuracy and communication protocol has been chosen. This sensor has additional functions, a smaller size, a smaller mass is qualified to the AEC-Q100 standard. The compared space-graded sensor is about 10 times more expensive than the automotive sensor in regard to acquisition costs. Based on this alternative sensor, two additional PCBs were designed with standard components and two versions of adjusted design guidelines (Fig. 1 middle and right). These three PCBs are showing the advantages of modern COTS in regard to saving volume. All three designs can be used for inertial navigation. In order to be able to use the mentioned advantages of this modern technology, however, a decisive step is missing-the qualification of the component, in particular with regard to radiation resistance.

To investigate the radiation resistance, the mentioned MEMS sensor as well as similary chosen voltage regulators (TL2575HV-05 Q1) is used. Radiation tests have been carried out to pre-qualify and determine the reliability of automotive components and classical power electronics components in this regard. A cobalt 60 source was used for irradiating the components with $\gamma$-rays to simulate long-term effects of space radiation. The total ionizing dose (TID) can be determined on the basis of the behavior of the components over irradiation. All of the components were irradiated simultaneously and their function was tested after they have been subjected to a certain dose. In total, the components were exposed to a dose of up to $28 \mathrm{krad}$. Since the components were out of operation during irradiation, the results provide only clues and serve as a preliminary selection test for basic suitability in a first step. After this first test phase, there will be further irradiation tests, where the components

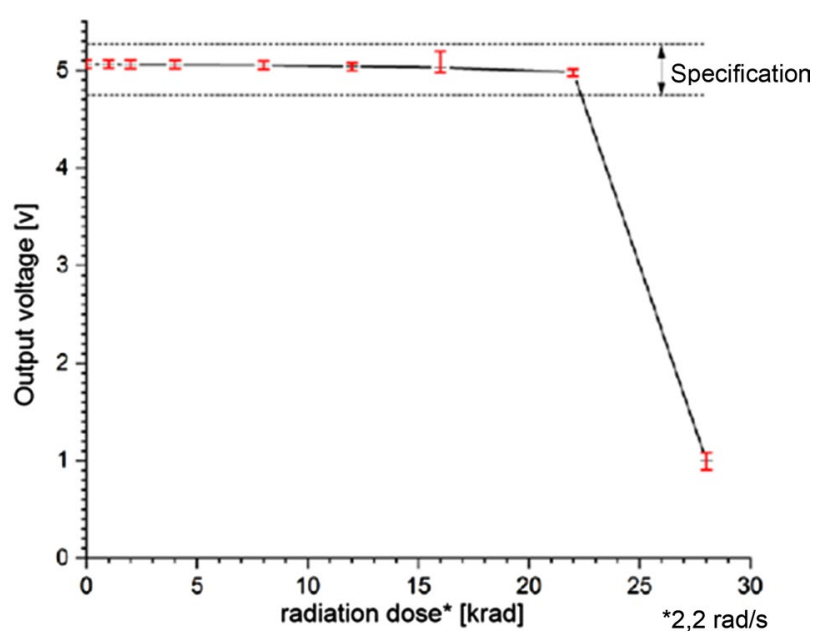

Fig. 2 Average output voltage of the voltage regulators as a function of the dose entered

are kept active during irradiation and their functionality is permanently monitored.

Figure 2 shows the average output voltages of the tested voltage regulators. The error bars show the distribution of the values for each individual component. Here, it can be seen that the output voltage of all 20 tested voltage regulators has reproducibly collapsed in the range between 22 and $28 \mathrm{krad}$. As the main function of the components is to regulate the voltage to a certain value, it has been determined that a malfunction is given if the output voltage is outside the specification.

In terms of the MEMS sensors, all four irradiated sensors were intact up to a maximum received dose of $30 \mathrm{krad}$.

Especially the results of the MEMS sensors are promising. Paired with high-saving potentials in weight, volume and costs, further investigations are of interest, particularly for these sensors [14].

\section{Additive manufacturing}

Additive manufacturing processes are already used for various CubeSat missions. The first satellite equipped with a printed structure was launched in 2016 [15]. Further example missions are presented in [16-18]. Besides structural components, propulsion $[19,20]$ or payload components [21, 22] can also benefit from additive manufacturing processes. In addition, additive manufacturing processes are used to integrate electrical functions into components [23]. Further examples are presented in the following sources [24, 25].

So in addition to cost-effective electronic components for the use in space, manufacturing technologies, such as additive manufacturing, can also generate immense benefits for satellite construction. The following section describes the 
expected advantages and will present first results. Furthermore, it is described how high-temperature thermoplastics of the classes polyetheretherketone (PEEK) and polyetherimide (PEI) can be processed within the fused-layer modelling (FLM) process, and the way they are pre-qualified for the use in space.

Additive manufacturing nowadays is widely spread and gains interest also in high-tech industries like the aerospace branch [26]. With the ongoing development of materials and processes, there are opportunities of adaption for costsavings and added value in the field of structural elements of satellites. The IRAS project, therefore, investigated how electronic components and cable harnesses can be integrated into structural components as functional components.

Figure 3 shows a corresponding demonstrator design developed by the German Aerospace Center (DLR). This design was the base for further test models. The approach envisages printing a honeycomb core between two fibre composite panels, which are designed to withstand high loads and can be fitted with cavities for cable harnesses and electronic components.

Investigations of the satellite design by the Institute for Space Systems at the University of Stuttgart (IRS), which take into account the developed technologies of the IRAS project, showed that the volume of the satellite can be significantly reduced. The density of functionality can also be increased by integrating local radiation protection elements

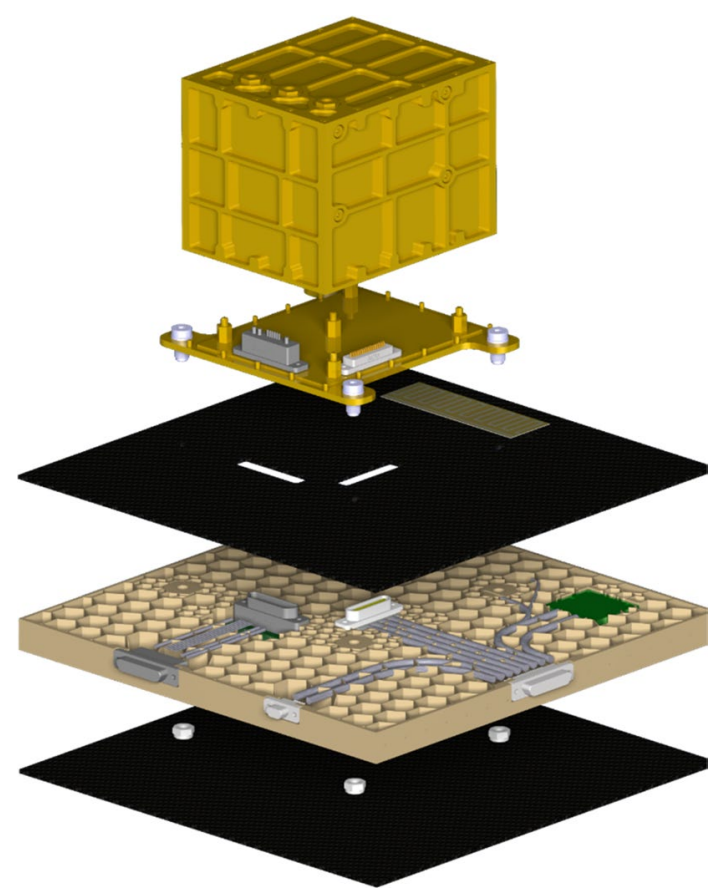

Fig. 3 Exploded view of the technology demonstrator with the GPS receiver unit into the honeycomb core to selectively protect the internal components.

For the structure in the in-orbit experiment, described below, the material PEEK was chosen-which is also a recommended thermoplastic in ECSS-Q-70-71a for use in space applications together with other high-temperature thermoplastics, such as PEI. Compared to other thermoplastics, PEEK has a high-temperature resistance and superior mechanical strength. At the same time, it is flame-retardant and tends to absorb only little moisture [27]. In addition, NASA's "EOIM-III Experiment" demonstrated a high resistance to $\gamma$-radiation [28].

However, the high-temperature resistance of the material and the associated high processing temperatures also imply special challenges for the processing. In addition to the strong heat distortion during cooling from the melt and the associated residual stresses in the component, the focus of the investigations is especially on the correlation between the material properties and the process parameters. The FLM filament of the company Fil-A-Gehr was used for the following investigations.

The influence of nozzle temperature and ambient temperature on the tensile strength according to DIN 527 is illustrated in Fig. 4.

It can be seen from the data that the mechanical properties are strongly dependent on high process temperatures. This is on the one hand due to the bond between the individual layers and on the other hand to the residual stress, which is intensified in the material by high cooling rates at low process temperatures. If correspondingly high ambient and nozzle temperatures were selected, a strength of more than $80 \%$ of the strength of the base material [29] could be achieved.

In addition to the material class PEEK, PEI was investigated, whereby the type ULTEM $^{\circledR} 9085$ was used in particular. Filaments of the companies 3DXTech (USA), Apium Additive Technologies GmbH (Germany) and

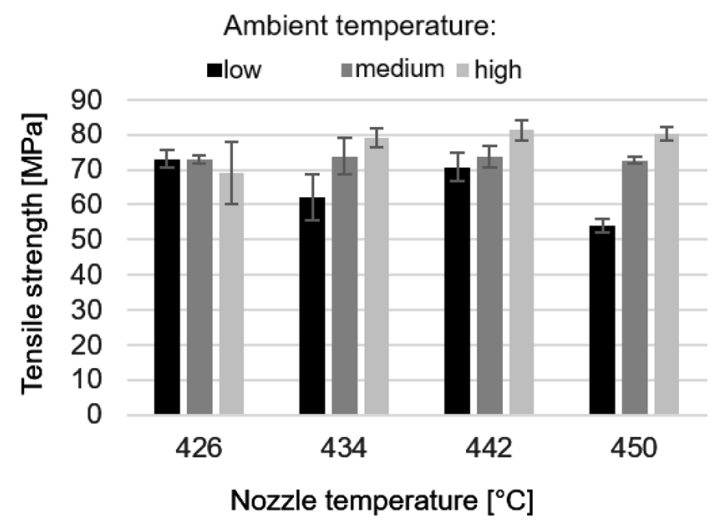

Fig. 4 Influence of process temperatures on the material properties of PEEK 
iSquared AG (Switzerland) were examined. For the further testing, PEI was preferred as result of the lower material costs - a comparission showed that PEEK is about double the price of PEI for commercially available Filaments. For the investigation, three test geometries were printed and evaluated with regard to dimensional accuracy, component warping, material oozing, detail imaging especially with regard to thin-walled structures as well as the optical overall picture. After a parameter optimization, it turned out that 3DXTech's material could be used to produce components that could best meet the above-mentioned requirements with the available equipment. Using a printing nozzle with an inner diameter of $0.4 \mathrm{~mm}$, wall structures with a minimum wall thickness of $0.5 \mathrm{~mm}$ had been produced. Due to the shrinkage behavior of the material during cooling, the distortion of printed components-i.e. the geometric deformation of the components after printing - had only been sufficiently minimized by changing the component geometry and, thus, minimizing the residual stress.

The aim of the approach was to print the material directly onto a fibre composite board. The matrix of this boards also consists of PEI. Therefore, shear tensile tests were used to investigate the extent to which a composite strength can be achieved. During the tests, two fiber composite panels were heated to $180^{\circ} \mathrm{C}$ as being printed on. The gap between these panels was then bridged by a printed structure. To investigate the bond, the two panels had been put to a tensile test. It could be proven that reducing the printing nozzle distance to the fibre composite panel during printing, the composite strength can be greatly improved. Here, the nozzle distance must be exactly adjusted to a distance lower than $0.01 \mathrm{~mm}$. If the distance was increased to $0.02 \mathrm{~mm}$, the bond strength was only partially given.

As the outgassing of materials for the use in space missions also needs to be considered, there has been further testing according to space standards. In order to evaluate the outgassing behaviour of the entire component consisting of a printed honeycomb structure made of Ultem ${ }^{\circledR} 9085$, the fibre composite board consisting of a PEI matrix and a film adhesive for bonding the upper cover layer (Redux 319), outgassing tests were carried out on the individual components based on the corresponding ECSS standard ECSSQ-ST-70-02C but on a first attempt under athmospheric pressure. The test resulted for all components in values far below $1 \%$ mass loss after reconditioning (recovered mass loss-RML). As these test results are promising, another test sequence will be carried out, applying all methods of the ECSS-Q-ST-70-02C.

Finally, sandwich panels with printed honeycomb cores, made of PEI with an area of approximately $200 \mathrm{~mm} \times 200 \mathrm{~mm}$, were produced. The models used were inspired by the design in Fig. 3, but without the integrated wire harness. The GPS-Box was simulated with a mass equivalent. One of the sandwiches can be sen in Fig. 5.

These were subjected to a vibration and thermal vacuum (TVAC) test. In the vibration test, two load profiles were run through after determining the resonance frequency:

1. Sinusoidal vibration profile (high level sine sweep, HLSS), in which the frequency range reached from 10 to $200 \mathrm{~Hz}$ with accelerations of 4-20 g.

2. Random vibration load (RVL) profile with a frequency range from 20 to $2000 \mathrm{~Hz}$ and random excitations.

The TVAC tests were oriented to the ECSS standard ECSS-Q-ST-70-04C. In the test, 100 cycles in the temperature range from -40 to $80{ }^{\circ} \mathrm{C}$ were carried out. The structures did not pass both tests and were destroyed by the loads. Cracks between the printed layers formed, which ran through the printed structures. In subsequent investigations of the printed structures, it was found that there were gas inclusions inside the polymer.

Figure 6 shows the layer structure with numerous circular air inclusions. It is assumed that the inclusions have their origin in water vapour, formed during the processing of insufficiently dried polymer filament.

During the melting process, water bound on the surface and in the polymer evaporates in the nozzle and is, thus, also extruded. These inclusions remain during solidification of the polymer in the component and significantly reduce its mechanical properties. This effect is likely to be responsible for the failure of the samples in the vibration and thermal vacuum tests. Further investigations with sufficiently dried polymer filament are still pending.

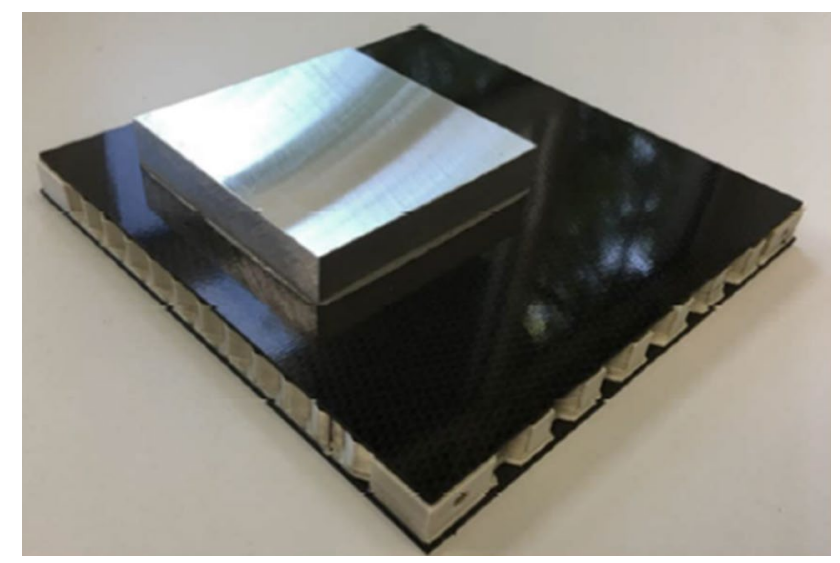

Fig. 5 Satellite sandwich with 3D-printed honeycomb core consisting of PEI 


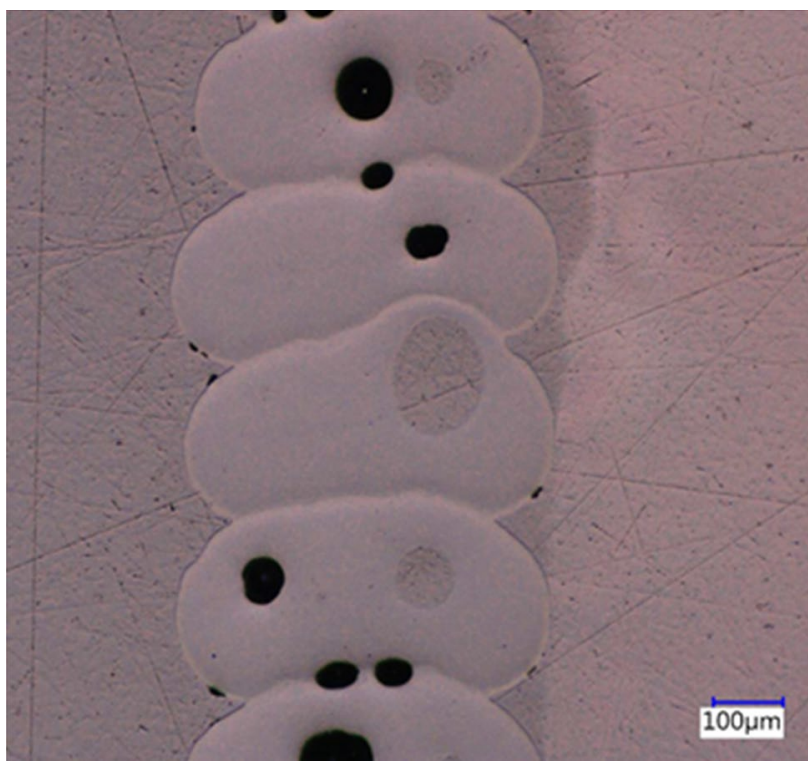

Fig. 6 Microsections of the layered composite with gas inclusions (dark shapes)

\section{In-orbit experiment}

In the context of this work, an integral satellite structure is presented, which combines the advantages of additive manufactured thermoplastic structures and miniaturized automotive electronics.

The structure consists of a sandwich with a printed core structure in which both, the wire harness and MEMS sensors for orientation and thermal sensing are integrated. In order to facilitate the use of automotive electronics under space conditions in the future, it will be investigated to what extent a radiation protection function can be embedded in the thermoplastic honeycomb core.

After both, the automotive electronics and partially the additively manufactured structure (from PEEK) will be fully examined for their suitability for space, the model presented below will serve as the first in-orbit test of the multifunctional structure. For this purpose, the sandwich structure is mounted as a payload on an end face of the 3U CubeSat SOURCE (https://www.ksat-stuttgart.de) of the University of Stuttgart and shall be tested in defined measuring orbits in a near-earth orbit. The use of a CubeSat limits the dimensions of the sandwich structure to $100 \times 100 \mathrm{~mm}^{2}$. Therefore, the integrated electronics are limited to the introduced MEMS sensor (Bosch SMI 130) which allows the measurement of acceleration and rotation rate as well as the necessary periphery of the sensor and the experiment. In addition, the wiring harness for the integrated electronics and a connector for connecting the sandwich to the rest of the satellite will be integrated. A preliminary model of the structure is shown in Fig. 7

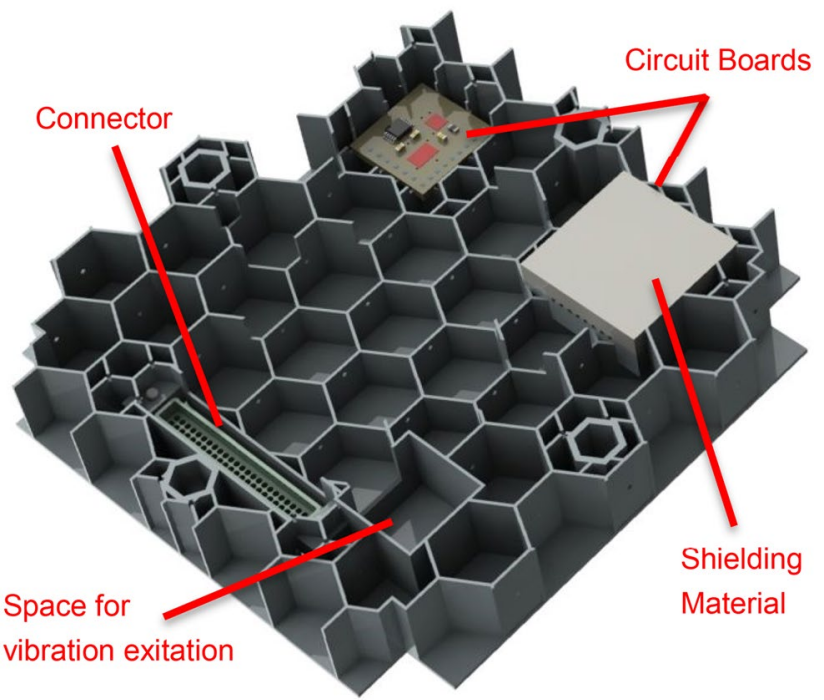

Fig. 7 Model of the first experimental setup based on the in-orbit experiment

where electronics are embedded in an adaptive honeycomb design.

The in-orbit qualification consists of two experiments. In the first experiment, the structural integrity of the printed sandwich is monitored by measuring the vibration response to a vibration excitation at the natural frequency of the sandwich. For this purpose, a top layer of the sandwich is excited to vibrate by an integrated piezo actuator. The response is then read via the acceleration sensors of the MEMS sensors. Damage within the structure as a consequence of the thermal vacuum cycles can be determined by changes in the vibration response. In order to minimize disturbance variables, such as temperature fluctuation, between the different measurements, all measurements are performed on defined measuring orbits with the same coverage.

The second experiment, which will be based on the function-integrated structure, consists of observing the behavior of automotive electronics in space. For this purpose, the two PCBs, which are identical to each other in design, will be monitored. A MEMS sensor and an analog-to-digital converter are mounted on each board. Both components are qualified according to the relevant automotive industry standard (AEC-Q100). The real radiation loads in the LEO should have an effect on the electronics. In order to record which radiation dose (TID relevant) the components are exposed to, the received $\gamma$-radiation is determined via the RADFET.

At the same time, the effect of an adaptive, additive shielding structure made of a tungsten-plastic mixture is to be investigated. Therefore, one of the boards is protected by a printed shield, while the other is integrated unprotected into the satellite wall. Over the lifetime and the measured 
radiation dose at the RADFETs, the shielding effect of the locally printed shields can, thus, be verified in an actual space mission under real conditions.

\section{Forecast}

In the following steps, the layout of the in-orbit experiment is finalized and built so that it can be tested within a Cubesat mission.

In addition, the properties of printed radiation protection structures made of tungsten-filled PEEK and their effectiveness against radiation will be investigated. For this purpose, investigations on the processability of the mixture as well as preliminary tests on the radiation protection effect are carried out on the basis of a $\gamma$-radiation source.

In order to further reduce manufacturing costs, it is currently being investigated whether alternative polymers from the field of engineering plastics can be used for structural elements. This could potentially save up to $90 \%$ of material costs. Even further cost savings are to be investigated, as alternative polymers could also result in use of less expensive equipment and lower energy consumption as a consequence of lower processing temperatures.

Acknowledgements Open Access funding provided by Projekt DEAL. This study is financed within the framework of the IRAS project ("Integrated Research Platform for Affordable Satellites") by the Ministry of Economics, Labour and Housing of the State of Baden-Württemberg under Contract number 3-4332.62-DLR/56.

Open Access This article is licensed under a Creative Commons Attribution 4.0 International License, which permits use, sharing, adaptation, distribution and reproduction in any medium or format, as long as you give appropriate credit to the original author(s) and the source, provide a link to the Creative Commons licence, and indicate if changes were made. The images or other third party material in this article are included in the article's Creative Commons licence, unless indicated otherwise in a credit line to the material. If material is not included in the article's Creative Commons licence and your intended use is not permitted by statutory regulation or exceeds the permitted use, you will need to obtain permission directly from the copyright holder. To view a copy of this licence, visit http://creativecommons.org/licenses/by/4.0/.

\section{References}

1. Burleigh, S.C., De Cola, T., Morosi, S., Jayousi, S., Cianca, E., Fuchs, C.: From Connectivity to advanced internet services: a comprehensive review of small satellites communications and networks. Wirel. Commun. Mob. Comput. (2019). https://doi. org/10.1155/2019/6243505

2. Foust, J.: Spacex's space-internet woes: despite technical glitches, the company plans to launch the first of nearly 12,000 satellites in 2019. IEEE Spectrosc. (2019). https://doi.org/10.1109/Mspec .2019 .8594798

3. Reid, T.G., Neish, A.M., Walter, T.F., Enge, P.K.: Leveraging commercial broadband leo constellations for navigating. In:
Proceedings of the 29th International Technical Meeting of the Satellite Division of the Institute of Navigation (Ion Gnss+ 2016). 29th International Technical Meeting of the Satellite Division of the Institute of Navigation (Ion Gnss+ 2016), Portland, Oregon, 12.09.2016-16.09.2016, pp. 2300-2314. Institute of Navigation (2016). https://doi.org/10.33012/2016.14729

4. Maral, G., De Ridder, J.-J., Evans, B.G., Richharia, M.: Low earth orbit satellite systems for communications. Int. J. Satell. Commun. (1991). https://doi.org/10.1002/Sat.4600090403

5. De Weck, O.L., De Neufville, R., Chaize, M.: Staged deployment of communications satellite constellations in low earth orbit. J. Aerosp. Comput. Inf. Commun. (2004). https://doi. org/10.2514/1.6346

6. Ruf, C.S., Chew, C., Lang, T., Morris, M.G., Nave, K., Ridley, A., Balasubramaniam, R.: A new paradigm in earth environmental monitoring with the cygnss small satellite constellation. Sci. Rep. (2018). https://doi.org/10.1038/S41598-018-27127-4

7. Sweeting, M.N.: Modern small satellites-changing the economics of space. Proc. IEEE (2018). https://doi.org/10.1109/Jproc .2018 .2806218

8. Nag, S., Lemoigne, J., De Weck, O.: Cost and risk analysis of small satellite constellations for earth observation. In: 2014 IEEE Aerospace Conference. 2014 IEEE Aerospace Conference, Big Sky, MT, USA, 01.03.2014-08.03.2014, pp. 1-16. IEEE (2014). https://doi.org/10.1109/Aero.2014.6836396

9. Del Corso, D., Passerone, C., Reyneri, L.M., Sansoe, C., Borri, M., Speretta, S., Tranchero, M.: Architecture of a small low-cost satellite. In: Kubátová, H. (Ed.) Proceedings, 10th euromicro conference on digital system design architectures, methods and tools. Dsd 2007: 29-31 August 2007, Lübeck, Germany. 10th Euromicro Conference on Digital System Design Architectures, Methods and Tools (DSD 2007), Lubeck, Germany, 8/29/2007-8/31/2007, pp. 428-431. IEEE Computer Society, Los Alamitos, California (2007). https://doi.org/10.1109/Dsd.2007.4341503

10. Ehresmann, M., Skalden, J., Fugmann, M., Harmansa, N., Fasoulas, S., Klinkner, S., Stäbler, T., Hümbert, S., Refle, O.: Iras: lowcost constellation satellite design, electric propulsion and concurrent engineering. In: 69th International Astronautical Congress (2018)

11. Díaz-Michelena, M.: Small magnetic sensors for space applications. Sensors (Basel Switzerland) (2009). https://doi.org/10.3390/ S90402271

12. Steffens, M., Hepp, F., Hoeffgen, S., Krzikalla, P., Metzger, S., Pellowski, F., Santin, G., Tighe, A., Weinand, U.: Characterization of novel lightweight radiation shielding materials for space applications. IEEE Trans. Nucl. Sci. (2017). https://doi.org/10.1109/ Tns.2017.2703312

13. Pignol, M.: Cots-based applications in space avionics. In: 2010 Design, Automation \& Test In Europe Conference \& Exhibition (Date 2010). 2010 Design, Automation \& Test in Europe Conference \& Exhibition (Date 2010), Dresden, 08.03.2010 12.03.2010, pp. 1213-1219. IEEE (2010). https://doi.org/10.1109/ Date.2010.5456992

14. Shea, H.R.: Effects of radiation on mems. In: Garcia-Blanco, S., Ramesham, R. (eds.) Reliability, Packaging, Testing, And Characterization of Mems/Moems and Nanodevices X. SPIE MoemsMems, San Francisco, California, Saturday 22 January 2011, 79280e. SPIE (2011). https://doi.org/10.1117/12.876968

15. Kramer, H.J.: Tomsk-Tpu-120: the first 3D printed cubesat mission. https://directory.eoportal.org/web/eoportal/satellite-missi ons/t/tomsk-tpu-120. Accessed 15 Aug 2019

16. Boschetto, A., Bottini, L., Eugeni, M., Cardini, V., Nisi, G.G., Veniali, F., Gaudenzi, P.: Selective laser melting of a 1u Cubesat structure. Design for additive manufacturing and assembly. Acta Astronaut. (2019). https://doi.org/10.1016/J.Actaa stro.2019.03.041 
17. Ampatzoglou, A., Tsantzalis, S., Mazarakos, D.E., Kostopoulos, V.: 3D printed frame for cubesat applications for low-earth orbit mission. IJCAET (2017). https://doi.org/10.1504/Ijcae t.2017.086923

18. The Australian Centre for Space Engineering Research: Unsw-Ec0 Qb50 Cubesat 3D printed structure (Acser): 3D printed structure. https://www.acser.unsw.edu.au/3d-printed-structure. Accessed 15 Aug 2019

19. Horais, B.J., Love, L.J., Dehoff, R.R.: The use of additive manufacturing for fabrication of multi-function small satellite structures. In: 27th Annual AIAA/USU Conference on Small Satellites (2013)

20. Marshall, W.M., Stegeman, J.D., Zemba, M., Macdonald, E., Shemelya, C., Wicker, R., Kwas, A., Kief, C.: Using additive manufacturing to print a cubesat propulsion system. In: Propulsion and Energy Forum. 51st AIAA/SAE/ASEE Joint Propulsion Conference. 51st AIAA/SAE/ASEE Joint Propulsion Conference, Orlando, FL (2015). https://doi.org/10.2514/6.2015-4184

21. Kief, C.: $3 \mathrm{D}$ printing the complete Cubesat. Advancing the use of additive manufacturing in space. In: 20150023528, NASA FS2015-03-32-ARC, ARC-E-DAA-Tn25943. Small Satellite Conference 2015; August 08, 2015-August 13, 2015; Logan, UT; United States (2015)

22. Kwas, A., Macdonald, E., Kief, C.J., Wicker, R., Soto, C., Bañuelos, L., Aarestad, J., Zufelt, B., Stegeman, J.D., Tolbert, C.: Printing multi-functionality: additive manufacturing for Cubesats. In: Space Conferences and Exposition. AIAA Space 2014 Conference and Exposition. AIAA Space 2014 Conference and Exposition, San Diego, CA, S181 (2014). https://doi.org/10.2514/6.2014-4193
23. Gutierrez, C., Salas, R., Hernandez, G., Muse, D., Olivas, R., Macdonald, E., Irwin, M.D., Wicker, R., Newton, M., Church, K., Zufelt, B.: Cubesat fabrication through additive manufacturing and micro-dispensing. Int. Symp. Microelectron. (2011). https:// doi.org/10.4071/Isom-2011-Tha4-Paper3

24. Espalin, D., Muse, D.W., Macdonald, E., Wicker, R.B.: 3d Printing Multifunctionality: Structures With Electronics, 5-8

25. Hümbert, S., Gleixner, L., Arce, E., Springer, P., Lengowski, M., Sakraker, I.: Material characterization of additively manufactured pa12 and design of multifunctional satellite structures. In: European Conference on Spacecraft Structures (2018)

26. Ernst \& Young: Ey'S global 3D printing report 2019

27. Domininghaus, H., Elsner, P., Eyerer, P., Hirth, T.: Kunststoffe. Eigenschaften Und Anwendungen, 8th edn. Vdi-Buch. Springer, Berlin (2012)

28. J. Scialdone, J., H. Clatterbuck, C., Ayres-Treusdell, M., Park, G., Kolos, D.: Atomic oxygen and space environment effects on aerospace materials flown with EOIM-3 experiment. NASA, Maryland (1996)

29. Victrex: Victrex ${ }^{\circledR}$ peek $450 \mathrm{~g}$ product data sheet. https://www.victr ex.com/ /media/datasheets/victrex_tds_450g.pdf. Accessed 3 Jun 2020

Publisher's Note Springer Nature remains neutral with regard to jurisdictional claims in published maps and institutional affiliations. 